\title{
Monitoring dispersion of carbon nanotubes in a thermosetting polyester resin
}

\author{
A. Battisti ${ }^{*}$, A.A. Skordos and I.K. Partridge \\ Composites Centre, School of Applied Sciences, Cranfield University, Cranfield, \\ Bedfordshire, MK43 0AL, UK
}

\begin{abstract}
The paper concerns the initial steps in the preparation of carbon nanotube containing nanocomposites of an isophthalic unsaturated polyester resin, prior to cure.

Developments in the nature of the rheology of the liquid samples were monitored as a function of the level of energy introduced via ultrasonic horn mixing and related to microscopic observations. On-line sampling, coupled with off-line viscosity measurements, is compared with on-line measurements of electrical resistivity of the mixture, in terms of the relative suitability of these techniques for real-time monitoring of nanofiller dispersion in the liquid mixtures. The shear thinning parameter, $\mathrm{N}$, derived from fitting Carreau model to the shear viscosity data, appears to provide a good qualitative indicator of the state of nanotube dispersion in the sample.
\end{abstract}

Keywords: A. Carbon nanotubes; A. Unsaturated polyester matrix; B. Electrical properties; C. Rheology; Dispersion

\footnotetext{
*a.battisti@cranfield.ac.uk tel: +44 (0) 1234750111 fax: +44 (0)1234 752473 Composites Centre - SAS, Cranfield University, Cranfield, Bedfordshire, MK43 0AL
} 


\section{Introduction}

The importance of the state of dispersion of solid nanofillers on the properties of the final cured nanocomposites has long been recognised [1-5]. In thermosetting nanocomposites the dispersion step is carried out in the liquid pre-polymer state. It is assumed that a high level of dispersion is required in this stage of the preparation of the nanocomposite, as the highly attractive forces between the nanoparticles can be expected to result in some degree of re-agglomeration during the process of cure $[6,7]$.

Whilst the use of microscopic techniques in the evaluation of sample structures is widespread, there is currently no direct standard means of quantifying the dispersion quality from structure images, either in the solid or in the liquid states. It is generally considered that the so called 'horn-sonication' is one of the most effective methods found to date to achieve a 'good quality' of dispersion nanoparticles in thermosetting resins $[8,9]$. Very little appears to be known about the effects of ultrasound energy introduction upon the progress of the dispersion process. The present study addresses this issue and explores the potential utilisation of rheological parameters, as an indirect, but quantifiable, measure of the 'dispersion quality'. On-line measurements of electrical resistivity are used alongside optical and scanning electron microscopy to assess dispersion and provide the basis for evaluation of monitoring via rheological parameters.

\section{Materials and Methods}

\subsection{Sample preparation}

The thermosetting polyester matrix was an isophthalic unsaturated polyester resin with a styrene content of $30 \mathrm{wt} \%$, produced by Scott Bader Co. Ltd. The 
appropriate curing agents for this grade of polyester are $0.02 \mathrm{wt} \%$ of cobalt octanoate, followed by the addition of $0.3 \mathrm{wt} \%$ methyl ethyl ketone peroxide.

The resin was modified by the addition of $0.25 \mathrm{wt} \%$ of multiwalled carbon nanotubes (MWCNTs) (Nanocyl@7000). As produced, the CNTs can be expected to be entangled, with a diameter in the region of $10 \mathrm{~nm}$ and length ranging from 0.1 to 10 microns.

The liquid CNT/resin pre-polymer mixtures, with no curing agent present, were prepared in a temperature controlled, $150 \mathrm{ml}$ capacity lab-scale 'plant', equipped with a condenser to prevent styrene evaporation (Fig. 1). The system comprises an overhang stirrer, a peristaltic pump, a flow-through ultrasonic horn, a sampling slot, a specially designed flow-through resistivity cell. The horn sonication was carried out by a Branson Sonifier ${ }^{\circledR}$ (model S-450D) digital cell disruptor, operating at a frequency of $20 \mathrm{kHz}$, with a maximum power of $400 \mathrm{~W}$ and equipped with a $12.7 \mathrm{~mm}$ diameter flow-through horn.

The preparation of the samples started with a manual mixing step, followed by mixing at $250 \mathrm{rpm}$ in the laboratory plant, at room temperature for 15 minutes. This preliminary mixing was designed to reduce the size of CNT aggregates, in order to avoid blocking of the circulating system. Subsequently, the temperature of the mixture was increased to $50{ }^{\circ} \mathrm{C}$ and the circulation of the material through the sonication horn started. The delivery of power by the sonication horn was controlled so that the temperature of the liquid remained in the 48 to $51^{\circ} \mathrm{C}$ range. This resulted in the creation of a modulated temperature profile with the heating step corresponding to intervals during which the sonicator was switched on, followed by cooling while the sonicator was switched off. Temperature readings in the bulk of material and in the flow-through 
resistivity cell as well as the measurements of the energy delivered by the sonifier were gathered by a National Instruments 4350 high-precision data acquisition board.

Experiments were performed at 20,55 and $100 \mathrm{~W}$ ultrasonication power input levels and the treatment duration was adjusted to reach a set amount of energy input, namely $1.5 \mathrm{~kJ} / \mathrm{g}$ of mixture. It should be noted that the power and energy input refer to that delivered by the ultrasonic horn rather than to the actual amount absorbed by the liquid nanocomposite. As the geometry and boundary conditions of the system are identical in all experiments, and the specific heat capacities of the materials investigated also do not vary widely, it is assumed that the ratio of energy absorbed to energy delivered remains relatively constant [10].

\subsection{Microscopic analysis techniques}

Figure 2 is a transmission electron microscopy (TEM) picture of the as-received CNTs. The as-received material had been de-aggregated in water by means of light sonication in a water bath. The sample for examination was then "fished out" onto a TEM copper grid and, after thorough drying, examined under a Philips CM 20 TEM, at an acceleration voltage of $120 \mathrm{kV}$.

\subsubsection{Liquid state microscopy}

The average state of dispersion of the CNTs in the polyester pre-polymer at any given stage of the liquid mixing was determined by examining the samples, mounted between a microscope slide and cover slip, under an optical transmission microscope. 


\subsubsection{Solid state microscopy}

The pre-mixed CNT/polyester sample, taken from the laboratory plant at a given stage of sonication, was combined with the appropriate amount of the required curing agents and painted as a thin layer directly onto an aluminium stub. It was then allowed to cure at ambient temperature for $24 \mathrm{~h}$ before examination. The internal structure of these samples was examined by utilising the newly developing "charge contrast imaging" scanning electron microscopy technique $[11,12]$. The electron microscope used was a FEI SFEG-SEM, and the operation parameters for the imaging were: working distance $5.0 \mathrm{~mm}$, aperture 5, spot size 4, TLD detector and accelerating voltage of $15 \mathrm{kV}$. The principle of this particular means of sample imaging is to use the normally undesirable phenomenon of sample charging in the electron beam. The potential difference between the matrix and the network of the conductive filler produces highly localised charging. As a consequence, the two components of the composite emit different amounts of secondary electrons and give rise to a high contrast image.

\subsection{Sampling and Rheology analysis}

During the sonication process samples were collected for rheological measurements. Bohlin CVO rheometer with $4 \% / 40 \mathrm{~mm}$ cone and plate geometry was used in steady shear mode, at $25^{\circ} \mathrm{C}$, and with sample size of $1.35 \pm 0.01 \mathrm{~g}$ of material. After 2 minutes of $100 \mathrm{~s}^{-1}$ pre-shear and 1 minute of stabilisation, a scan of viscosity against shear rate was performed, from 0.1 to $100 \mathrm{~s}^{-1}$. The relationship between the shear rate and the viscosity was fitted using the general Carreau viscosity model [13-15],

$$
\eta=\eta_{\infty}+\left(\eta_{0}-\eta_{\infty}\right)\left(1+\lambda^{2} \cdot \gamma^{2}\right)^{-N}
$$


Here $\lambda$ denotes a relaxation time, and $N$ a shear thinning exponent. Both are fitting parameters that describe the relationship between the viscosity $\eta$ of the pre-polymer and the shear rate $\gamma . \eta_{0}$ and $\eta_{\infty}$ are the limiting viscosities, at very low and at very high shear rates respectively.

The fitting was performed using a least-squares method with the generalized reduced gradient method implemented in Microsoft Excel [16].

\subsection{Liquid electrical resistivity measurements}

The electrical resistivity of the liquid sample was measured online, using a home-built flow-through resistivity cell, shown in Fig. 3. The cell has two copper electrodes arranged in a coaxial configuration. The inner electrode is a $3 \mathrm{~mm}$ diameter rod and the outer electrode an $8 \mathrm{~mm}$ internal diameter cylinder. The sensing length is $20 \mathrm{~mm}$ and the two electrodes are kept apart by non-conductive polyoxymethylene supports, designed for unhindered flow of the liquid material.

A Keithley 6220 high precision current source and a Keithley 2182A nanovoltmeter were interfaced to a computer via a GPIB-to-USB converter. An inhouse software code has been utilised to drive the current source to the nanovoltmeter and to collect the raw data in the form of current and voltage. The resistivity of the sample is given by:

$$
\rho=\frac{2 \pi L R}{\ln \left(\frac{r_{o}}{r_{i}}\right)}
$$

Here $R$ is the measured resistance, $L$ denotes the sensing length $(20 \mathrm{~mm}), r_{o}$ is the internal radius of the outer cylinder $(4 \mathrm{~mm})$, and $r_{i}$ the radius of the inner rod $(1.5 \mathrm{~mm})$. 
Temperature of the sample was measured using a k-type thermocouple placed at the entry point of the conductivity cell. A typical thermal profile during ultrasonication is shown in Fig. 4, alongside the corresponding resistivity measurements. As the resistivity is highly sensitive to the instantaneous temperature, a correction was introduced to remove the effect of temperature changes. This was done by fitting the following model to resistivity versus temperature data, acquired during the cooling steps of the ultrasonication process:

$$
\rho=\rho_{o} e^{-\frac{\beta}{T-T_{o}}}
$$

Here $\rho_{o}$ is the resistivity at a reference temperature $T_{o}$ and $\beta$ is a fitting parameter corresponding to the slope of a log-log plot. The reference temperature chosen was $51^{\circ} \mathrm{C}$.

\section{Results and Discussion}

\subsection{Evolution of Rheological parameters: off-line measurements}

Figure 5 is a plot of the shear viscosity of the CNT/polyester pre-polymer mixture, against strain rate in the range 0.1 to $100 \mathrm{~s}^{-1}$. Representative plots are presented for samples that have undergone horn sonication at $55 \mathrm{~W}$ to total energy input levels of 0.3 and $1.3 \mathrm{~kJ} / \mathrm{g}$ (specific energy referred to a gram of sample mixture) and these are compared with a hand-mixed control sample. Referring to the parameters of the Carreau model (eq. 1), the absolute values of the low shear rate viscosity $\eta_{0}$, the high shear rate viscosity $\eta_{\infty}$ and the shear thinning parameter $N$ all increase across the entire measurement frequency range as more sonication energy is delivered to the system. The change in the shear thinning nature of the liquid mixtures is the most pronounced, with 
$\mathrm{N}$ increasing from 0.0046 to 0.207 and 0.317 in these three samples, respectively before sonication, sonication energy $0.3 \mathrm{~kJ} / \mathrm{g}$ and $1.3 \mathrm{~kJ} / \mathrm{g}$. This is a not unexpected effect of the improved dispersion of the CNTs in the mixtures [17-21], as evidenced by the presence of large nanotube clusters in the control sample (Fig.6a) and the absence of such large aggregates in the sample that had been horn-sonicated to $1.3 \mathrm{~kJ} / \mathrm{g}$ level (Fig.6b).

In terms of sensitivity and robustness the shear thinning parameter proves preferable to the other parameters and thus has been chosen as a qualitative measure of the level of dispersion in further experiments, which were designed to evaluate the effect of the sonication power. Figure 7 shows how the shear thinning parameter $\mathrm{N}$ changes in response to different total energy inputs, delivered at three different ultrasonication power levels, namely 20,55 and $100 \mathrm{~W}$. The value of $\mathrm{N}$ rises rapidly, from close to zero in the unsonicated samples, up to energy input of about $0.6 \mathrm{~kJ} / \mathrm{g}$, and then it changes only gradually, reaching a limiting value of just over 0.3 in highly sonicated samples. The ultrasonication at 20 and $100 \mathrm{~W}$ appears to be more efficient than at $55 \mathrm{~W}$. This could be a real result, suggesting a complex interplay between energy input and mechanisms of energy absorption. However, it is just as likely that the sonication efficiency is highly influenced by the exact positioning of the ultrasonic horn within the mixing vessel [10]. Given the limited number of experiments reported here, it is not possible to make this judgement. Nevertheless, the variations between the shear thinning parameter vs ultrasonication energy curves obtained at the different power levels are relatively small, indicating that energy is the main controlling factor of the dispersion process. 
Charge contrast imaging scanning electron microscopy examination of corresponding cured specimens shows a clear initial increase in the quality of the dispersion, up to sonication energy input of $0.6 \mathrm{~kJ} / \mathrm{g}$. Above this level the CNTs appear evenly distributed in the material and it becomes difficult to perceive any further change (see Fig.8).

\subsection{Electrical Resistivity Monitoring: on-line measurements}

The indication of the dispersion quality changes through the sonication process are corroborated by the accompanying changes in the DC electrical conductivity of the samples. The order of the resistivity against energy input curves in Fig.9 is out of sequence with the increasing power level, as observed previously in Fig.7. The changes in resistivity can be interpreted in terms of the development of a percolating system [22]; the microstructure of the sample changes from a few large isolated clusters of CNTs to predominantly separate individual nanotubes and a few smaller remaining clusters. As a consequence of the sonication, the number of individual conductive particles increases and the resistivity decreases slowly in the early stage of the process (phase 1 in Fig.9). Once the concentration of dispersed filler reaches the electrical percolation threshold, the resistivity drops sharply (phase 2), by three to four orders of magnitude. Any further improvement in the dispersion contributes only very slightly to the effectiveness of the conductive network and the resistivity levels off to a final value (phase 3). The resistance of the material sonicated at the highest power level (100 W) exhibits a slow upward drift in the latest stages of the process. This could be an indication of eventual damage to the nanotubes by some form of 'oversonication'. The electrical measurements give the same qualitative indication of the changes in the dispersion of the CNTs in the polyester resin as that provided by the viscosity 
measurements. The on-line nature of the electrical measurements is an added attraction. However, as mentioned previously in section 2.4 , there is a need for the instantaneous temperature correction in order to obtain reliable data.

\section{Conclusions}

The results of this study demonstrate the potential use of rheological properties as a metric of dispersion of carbon nanotubes in liquid polyester pre-polymer. Shear thinning is identified as the parameter with the greatest sensitivity to variations in dispersion state, combined with a high level of robustness in parameter estimation. The technique requires sampling and off-line measurement of viscosity over a range of strain rates. The duration of the procedure is in the range 5-10 min, which makes it acceptable for use in the context of industrial scale quality control.

The evolution of electrical resistivity during ultrasonication treatment closely follows the results obtained by rheometry. Measurement of resistance provides the means for on-line dispersion monitoring in the case of conductive nanofillers and as such it presents an opportunity for quality control in the processing of nanocomposites. However, electrical behaviour can be influenced by other phenomena such as detail of nanoparticle network formation that may hinder the correlation with the state of dispersion.

\section{Acknowledgements}

The work reported here was funded in part by EPSRC "Speculative Research in Engineering" grant EP/C 509730 and in part by Cranfield University IMRC. Assistance by Dr David Ayre in the microscopic analysis is gratefully acknowledged. 


\section{References}

1. Hussain F, Hojjati M, Okamoto M, Gorga RE. Review article: Polymer-matrix nanocomposites, processing, manufacturing, and application: An overview. Journal of Composite Materials 2006;40(17):1511-75.

2. Thostenson ET, Li C, Chou T. Nanocomposites in context. Composites Science and Technology 2005;65(3-4):491-516.

3. Thostenson ET, Ren Z, Chou T. Advances in the science and technology of carbon nanotubes and their composites: A review. Composites Science and Technology 2001;61(13):1899-912.

4. Coleman JN, Khan U, Blau WJ, Gun'ko YK. Small but strong: A review of the mechanical properties of carbon nanotube-polymer composites. Carbon 2006;44(9):1624-52.

5. Xie X, Mai Y, Zhou X. Dispersion and alignment of carbon nanotubes in polymer matrix: A review. Materials Science and Engineering R: Reports 2005;49(4).

6. Schueler R, Petermann J, Schulte K, Wentzel H. Agglomeration and electrical percolation behavior of carbon black dispersed in epoxy resin. Journal of Applied Polymer Science 1997;63(13):1741-6.

7. Sandler JKW, Kirk JE, Kinloch IA, Shaffer MSP, Windle AH. Ultra-low electrical percolation threshold in carbon-nanotube-epoxy composites. Polymer 2003;44(19):5893-9.

8. Qian D, Dickey EC, Andrews R, Rantell T. Load transfer and deformation mechanisms in carbon nanotube-polystyrene composites. Applied Physics Letters 2000;76(20):2868-70. 
9. Liao Y, Marietta-Tondin O, Liang Z, Zhang C, Wang B. Investigation of the dispersion process of SWNTs/SC-15 epoxy resin nanocomposites. Materials Science and Engineering A 2004;385(1-2):175-81.

10. Hielscher T. Ultrasonic production of nano-size dispersions and emulsions.

European nano systems 2005; 14-16 December; Paris, France: TIMA Editions; 2005.

11. Kovacs JZ, Andresen K, Pauls JR, Garcia CP, Schossig M, Schulte K, Bauhofer W. Analyzing the quality of carbon nanotube dispersions in polymers using scanning electron microscopy. Carbon 2007;45(6):1279-88.

12. Loos J, Alexeev A, Grossiord N, Koning CE, Regev O. Visualization of single-wall carbon nanotube (SWNT) networks in conductive polystyrene nanocomposites by charge contrast imaging. Ultramicroscopy 2005;104(2):160-7.

13. Carreau PJ. Rheological equations from molecular network theories. Trans Soc Rheol 1972;16(1):99-127.

14. Yasuda K, Armstrong RC, Cohen RE. Shear flow properties of concentrated solutions of linear and star branched polystyrenes. Rheologica Acta 1981;20(2):163-78. 15. Shenoy AV. Rheology of filled polymer systems. Springler-Verlag; 1999. . 16. Fylstra D, Lasdon L, Watson J, Waren A. Design and use of the microsoft excel solver. Interfaces 1998;28(5):29-55.

17. Seyhan AT, Gojny FH, Tanoglu M, Schulte K. Critical aspects related to processing of carbon nanotube/unsaturated thermoset polyester nanocomposites. European Polymer Journal 2007;43(2):374-9.

18. Ma AWK, Mackley MR, Rahatekar SS. Experimental observation on the flowinduced assembly of carbon nanotube suspensions to form helical bands. Rheologica Acta 2007;46(7):979-87. 
19. Rahatekar SS, Koziol KKK, Butler SA, Elliott JA, Shaffer MSP, Mackley MR, Windle AH. Optical microstructure and viscosity enhancement for an epoxy resin matrix containing multiwall carbon nanotubes. Journal of Rheology 2006;50(5):599610.

20. Wichmann MHG, Sumfleth J, Fiedler B, Gojny FH, Schulte K. Multiwall carbon nanotube/epoxy composites produced by a masterbatch process. Mechanics of Composite Materials 2006;42(5):395-406.

21. Shaffer MSP, Fan X, Windle AH. Dispersion and packing of carbon nanotubes. Carbon 1998;36(11):1603-12.

22. Clingerman ML, King JA, Schulz KH, Meyers JD. Evaluation of electrical conductivity models for conductive polymer composites. Journal of Applied Polymer Science 2002;83(6):1341-56.

\section{Figure Captions}

Fig. 1 Polyester/CNT mixing and dispersion setup

Fig. 2 Transmission electron micrograph of as-received multiwalled carbon nanotubes Fig. 3 Flow-through electrical resistivity cell

Fig. 4 Temperature and resistivity profile during sonication

Fig. 5 Viscosity as a function of strain rate at various ultrasonication energies during the treatment at $55 \mathrm{~W}$

Fig. 6 Liquid state optical transmission micrographs of (A) the untreated material and;

(B) the material after $1.55 \mathrm{~kJ} / \mathrm{g}$ sonication at $55 \mathrm{~W}$

Fig. 7 Evolution of shear thinning parameter $\mathrm{N}$ during ultrasonication 
Fig. 8 Charge contrast imaging SEM of cured samples. The liquid mixtures had been sonicated at $55 \mathrm{~W}$ to different energy input levels: (A) $0.32 \mathrm{~kJ} / \mathrm{g}$ (B) $0.63 \mathrm{~kJ} / \mathrm{g}$ (C) 1.55 $\mathrm{kJ} / \mathrm{g}$. The significant apparent depth of focus is a consequence of the charging phenomenon [12].

Fig. 9 Evolution of resistivity during ultrasonication 


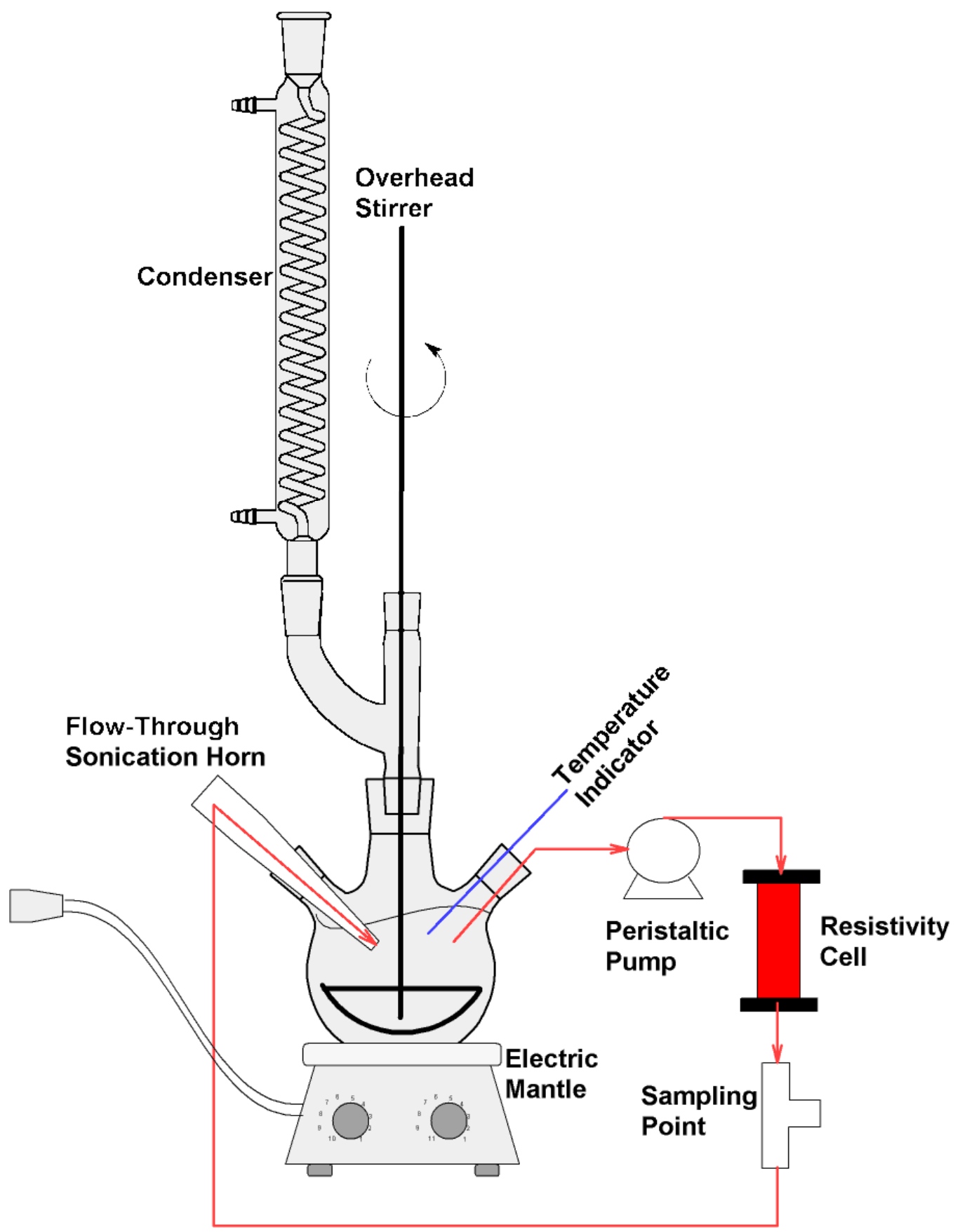




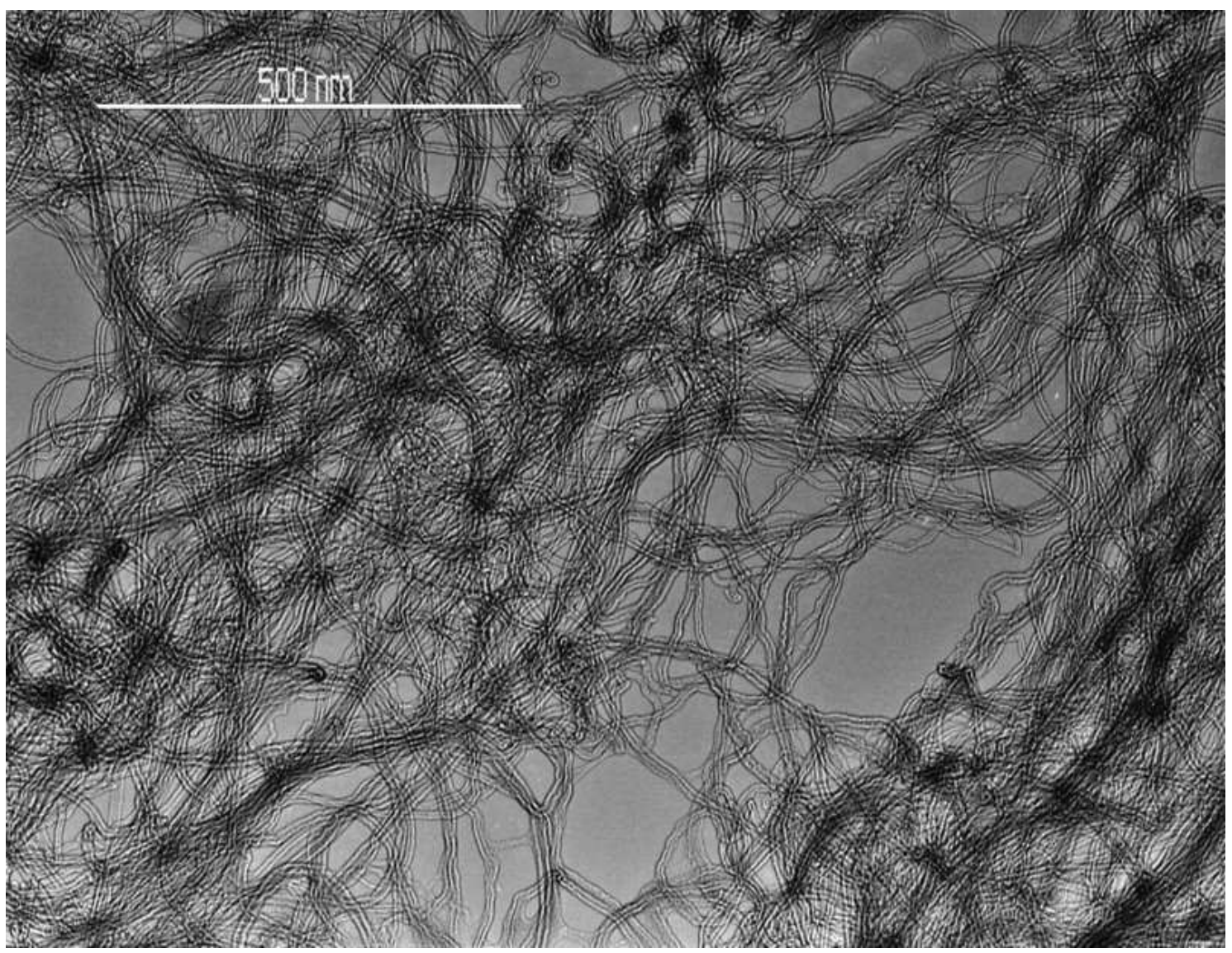




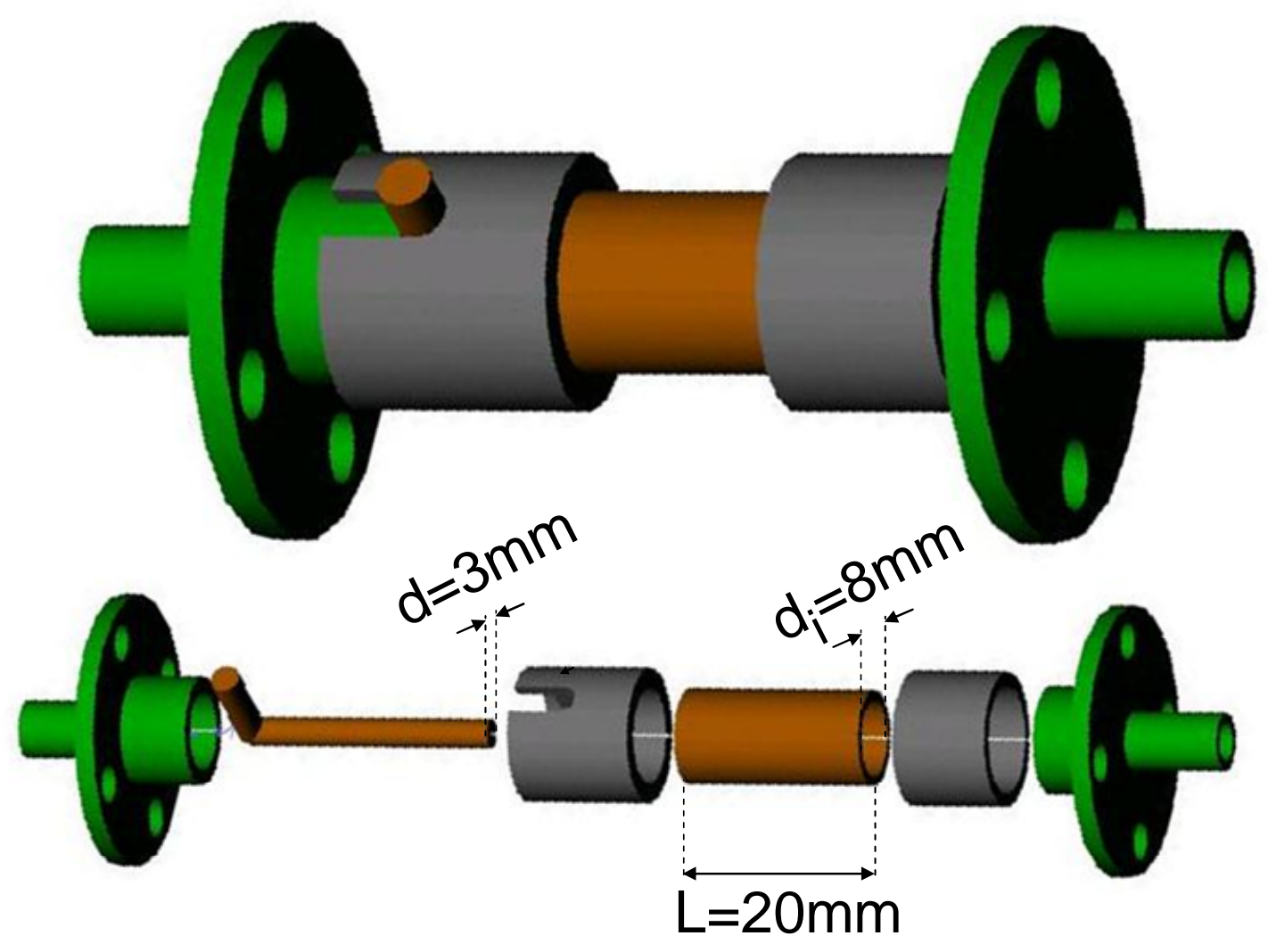




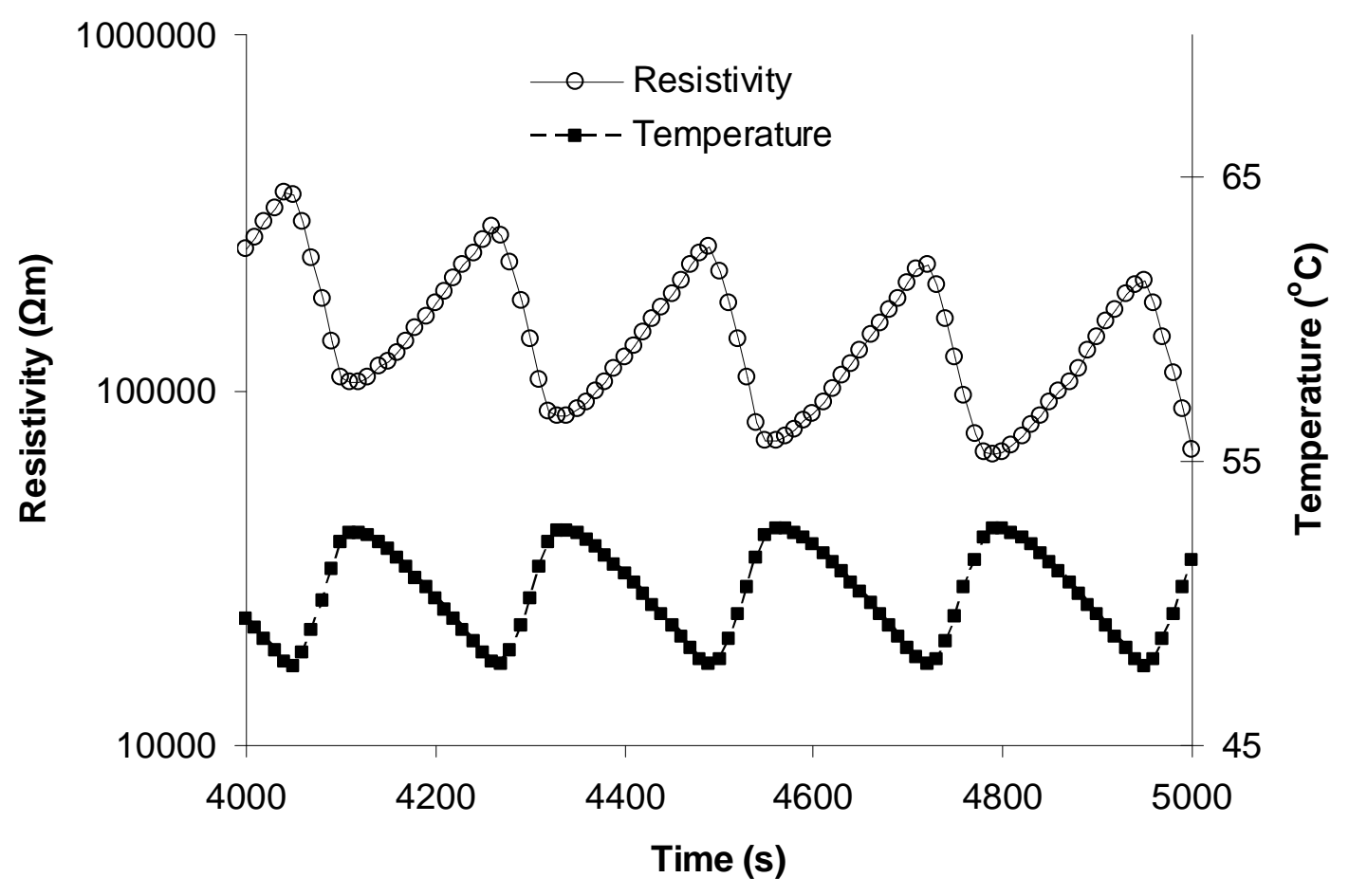




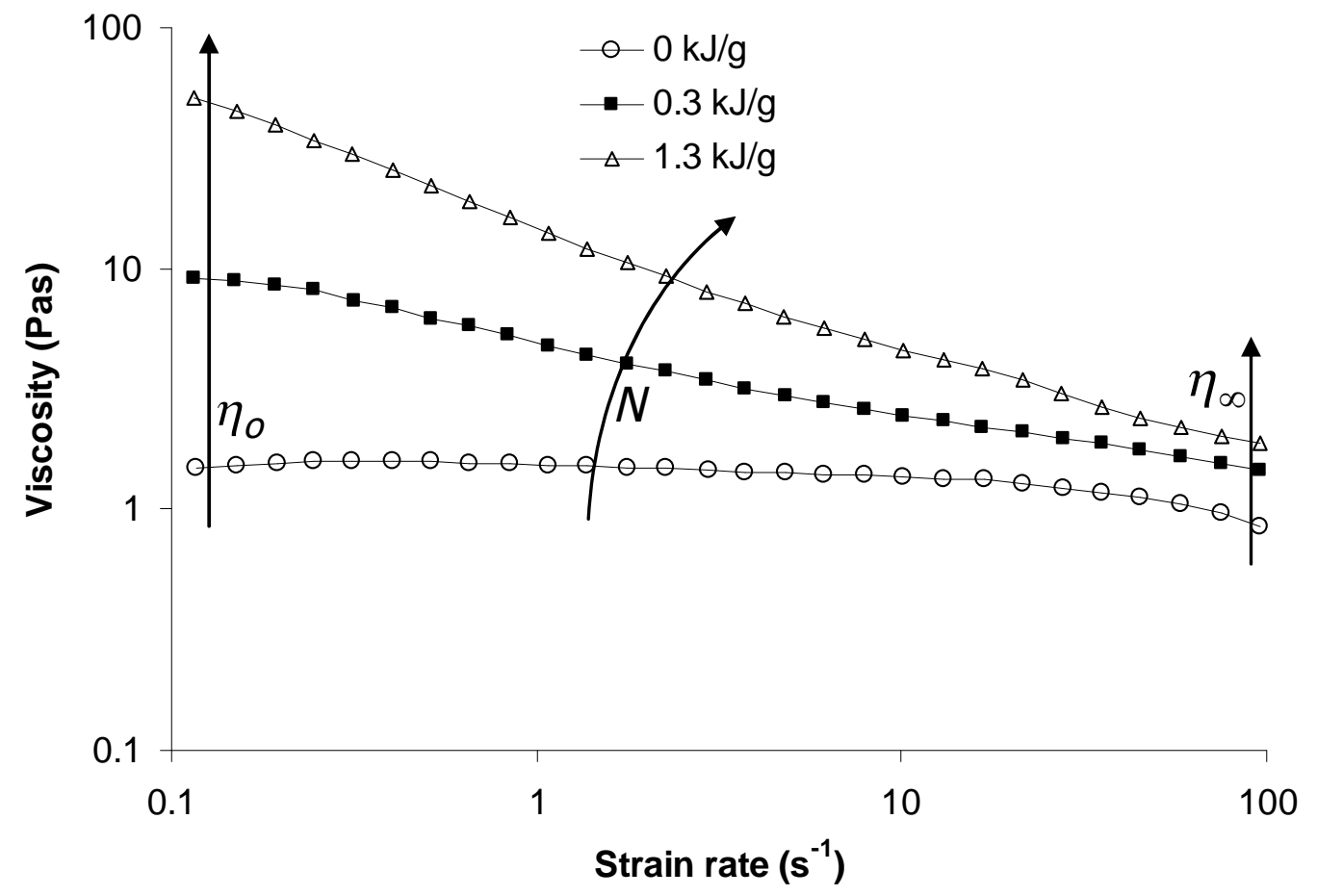



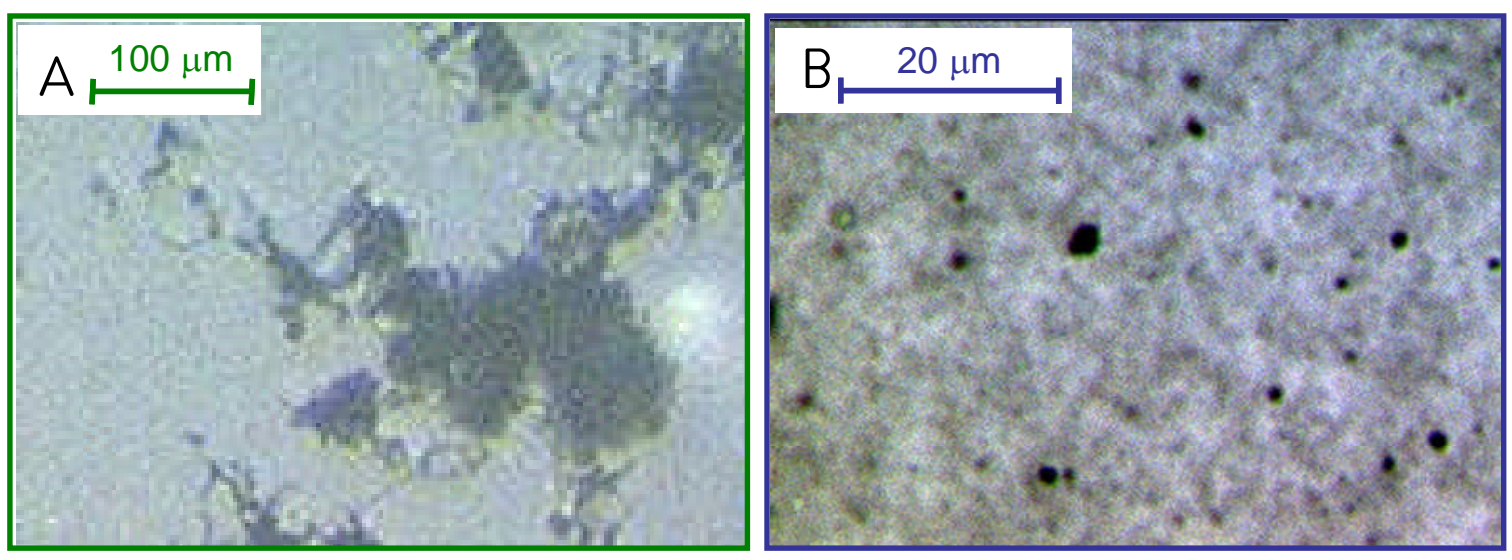


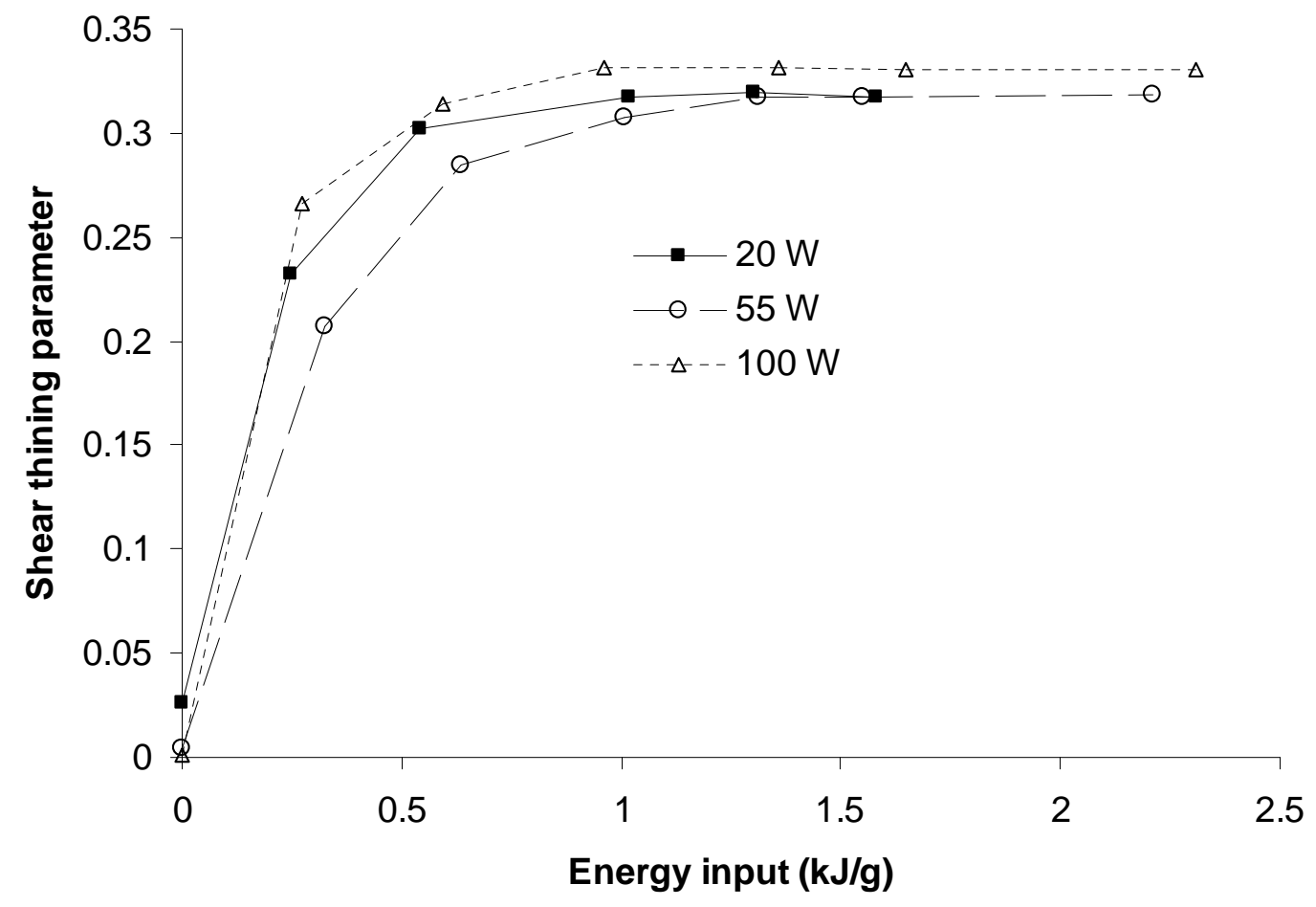



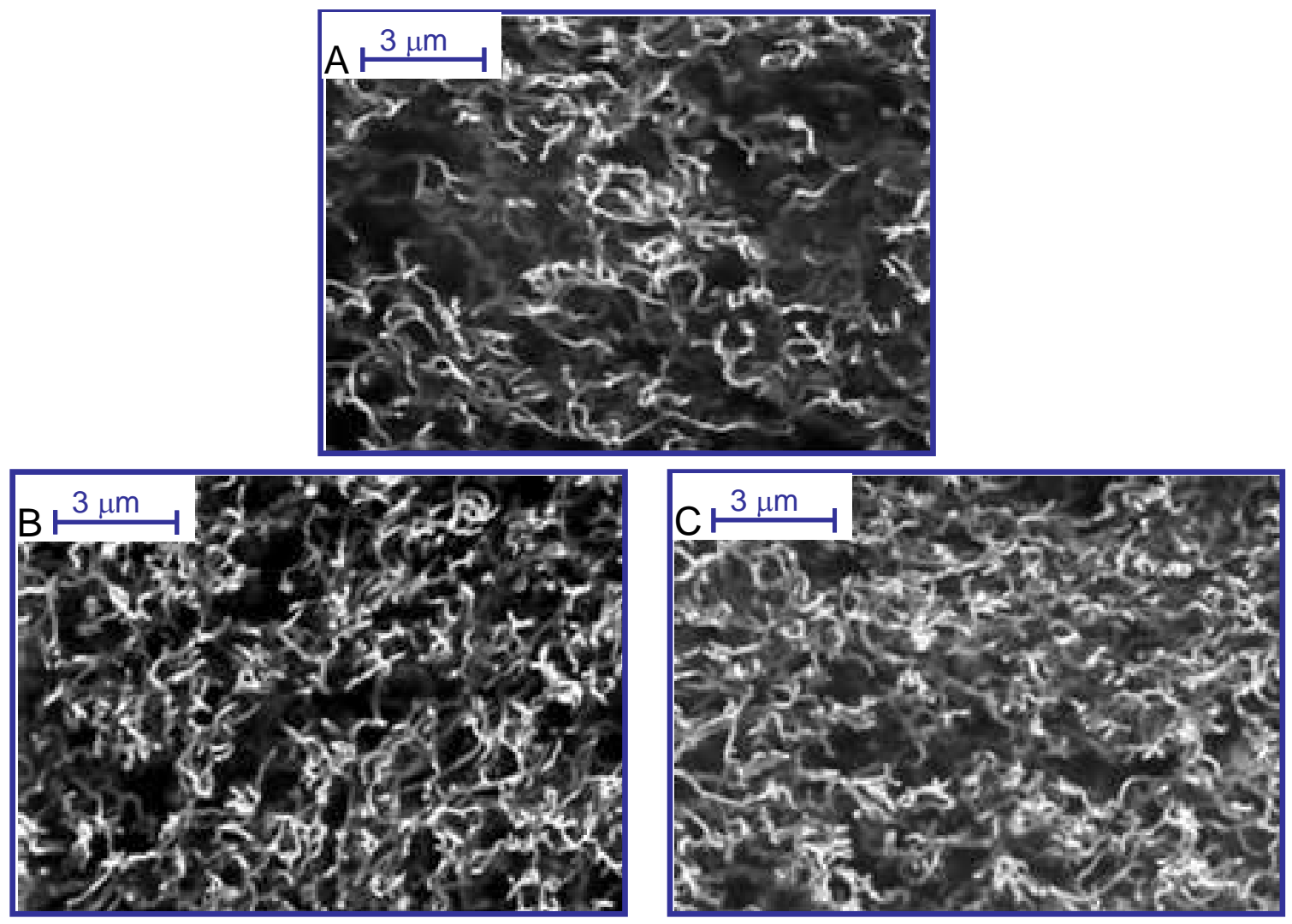


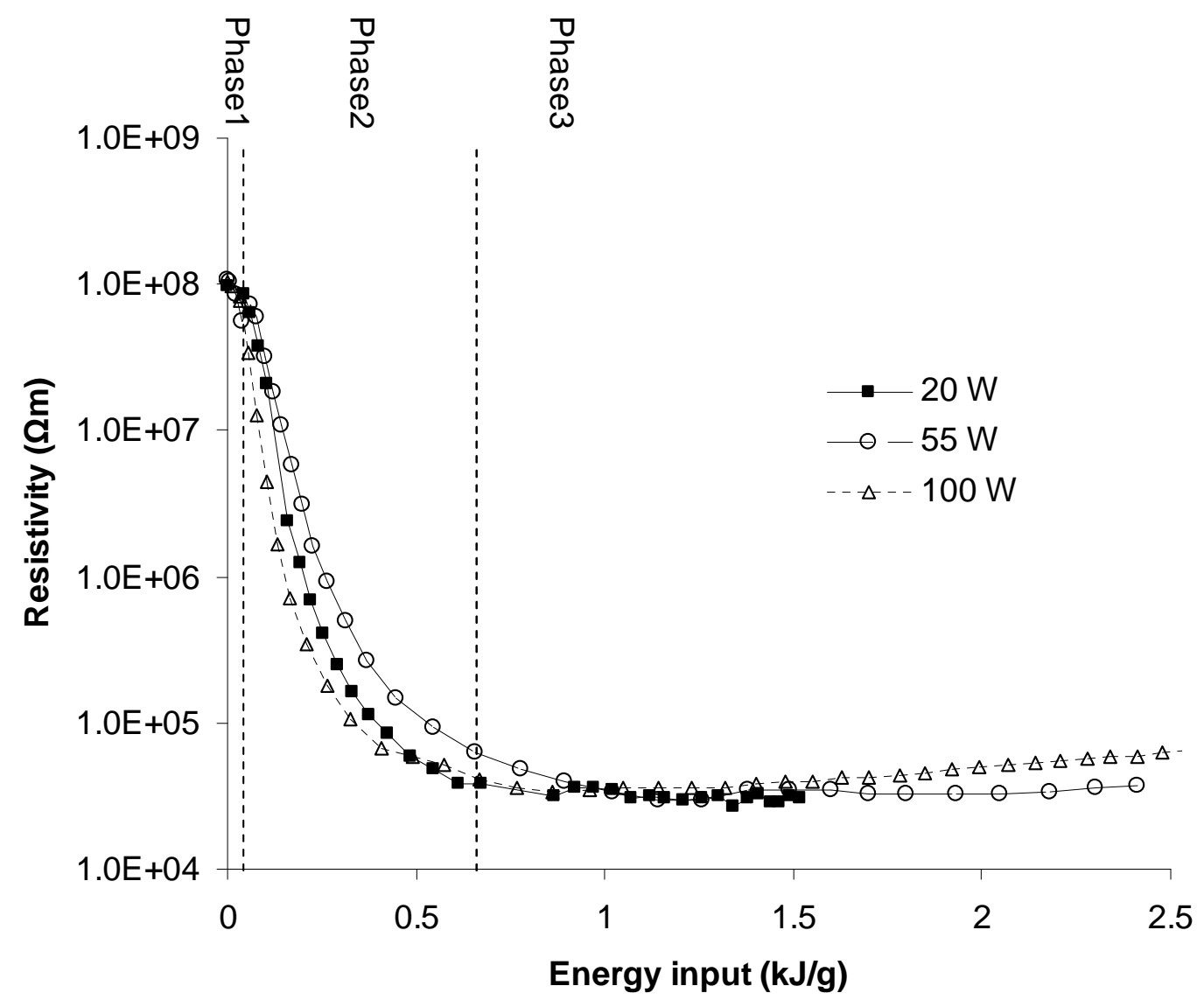

